\title{
O TRABALHO NA VIDA DOS ADOLESCENTES: ALGUNS FATORES DETERMINANTES PARA O TRABALHO PRECOCE ${ }^{1}$
}

Beatriz Rosana Gonçalves Oliveira ${ }^{2}$

Maria Lúcia do Carmo Cruz Robazzi

Oliveira BRG, Robazzi MLCC. 0 trabalho na vida dos adolescentes: alguns fatores determinantes para o trabalho precoce. Rev Latino-am Enfermagem 2001 maio; 9(3):83-9.

Este estudo objetiva explicitar alguns determinantes que impelem os adolescentes ao trabalho através de sua compreensão da realidade e dos agravos à saúde do processo de trabalho. Estudo qualitativo, fundamentado no materialismo histórico, metodologia da hermenêutica dialética. Os dados empíricos foram coletados numa instituição formadora/mediadora para o mercado de trabalho em Cascavel - PR, utilizando-se a análise documental e a entrevista semi-estruturada. Os determinantes encontrados para o trabalho precoce foram: pobreza, desigualdade social, concentração de renda, demanda de mercado, oferta educacional, qualidade do ensino, constituição familiar, determinações do sistema de produção e necessidade de ganhar a vida por conta própria.

UNITERMOS: adolescente, trabalho precoce

\section{WORK IN THE LIFE OF ADOLESCENTS: FACTORS DETERMINING EARLY START IN THE WORK MARKET}

This study aims at clarifying determinant factors which impel adolescents to work through the comprehension of their reality and of the damages to health caused by the work process. It is a qualitative study based on the historical materialism and on the dialectic hermeneutics methodology. Empirical data were collected from an educational/mediating institution which qualified students for the labor market in Cascavel$P R$, Brazil by means of documental analysis and semi-structured interviews. The determinant factors leading to work at an early age were: poverty, social inequality, income concentration, market demand, educational provision, educational standards, family constitution, determinations by the production system and the need for adolescents to have their own income.

KEY WORDS: adolescent, labor market, work conditions

\section{EL TRABAJO EN LA VIDA DE LOS ADOLESCENTES: ALGUNOS FATORES DETERMINANTES DEL TRABAJO PRECOZ}

El estudio busca explicar algunos de los factores que empujan a los adolescentes a trabajar, sus opciones, su comprensión de la realidad y de los daños a la salud a los cuales están sometidos en el proceso de trabajo. Se trata de un estudio cualitativo, basado en el referencial teórico del materialismo histórico, teniendo como metodología la hermenéutica dialéctica. Los datos empíricos fueron recolectados en una institución formadora/mediadora para el mercado de trabajo en el municipio de Cascavel - $P R$, utilizándose el análisis documental y la entrevista semi-estructurada. Los determinantes encontrados para el hecho de que se hayan insertado en edad precoz en el mercado de trabajo fueron: la pobreza, la desigualdad social, la concentración de renta, la demanda del mercado de trabajo para el joven, la oferta educacional, la calidad de la enseñanza a la cual tienen acceso, la constitución familiar, las determinaciones del sistema de producción y la necesidad de ganarse la vida por sí mismos.

TÉRMINOS CLAVES: adolescentes, trabajo precoz, determinantes del trabajo

\footnotetext{
${ }^{1}$ Parte da dissertação de mestrado apresentada ao Programa de Pós-Graduação da Escola de Enfermagem de Ribeirão Preto da Universidade de São Paulo, área: Enfermagem Fundamental

${ }^{2}$ Enfermeira, Docente do Curso de Enfermagem da Universidade Estadual do Oeste do Paraná - UNIOESTE, Mestre - Área: Enfermagem Fundamental; ${ }^{3}$ Enfermeira, Professor Titular. Escola de Enfermagem de Ribeirão Preto da Universidade de São Paulo, Centro Colaborador da OMS para o desenvolvimento da pesquisa em Enfermagem
} 


\section{INTRODUÇÃO}

Existem algumas questões relativas ao trabalho do jovem, como as condições concretas em que laboram, os determinantes fundamentais e a lógica de seu engajamento no trabalho, as conseqüências da inserção no mercado e o significado do labor, que estaremos desenvolvendo a seguir, objetivando compreender o conjunto destes fatores de maneira articulada, tanto no que diz respeito aos momentos que compõem o cotidiano do adolescente, como família, escola, trabalho e lazer, quanto aos fenômenos sociais mais abrangentes relacionados ao trabalho precoce. Adotar como objeto de estudo a questão do trabalho precoce é uma tarefa complexa, que perpassa a defesa da criança e do jovem e a garantia de seus direitos individuais como cidadãos. Ganha espaço no plano da consciência coletiva, projetando-se para a ação política na forma de programas adotados por governos e pela sociedade. Embora a preocupação e o combate ao trabalho precoce tenham um apelo humanitário, este continua existindo e proliferando ${ }^{(1)}$. Tal constatação nos instiga a discutir esta temática, especificamente os fatores determinantes que levam o jovem ao trabalho. 0 referencial teórico que lhe dá suporte é o materialismo histórico, sendo os aspectos discutidos apreendidos do contexto social dos adolescentes ${ }^{(2)}$. A metodologia que sustenta a análise dos dados é a hermenêutica dialética, utilizando-se para a coleta de dados a análise documental e a entrevista semi-estruturada ${ }^{(3)}$. Os dados foram coletados a partir das questões norteadoras, com nove adolescentes do sexo masculino, de um programa de formação para o trabalho no município de Cascavel - PR e analisados a luz do referencial adotado por meio de categorias de análise. A discussão apresentada a seguir é integrante de uma das categorias de análise obtidas na construção do trabalho, denominada fatores determinantes para 0 trabalho precoce e enfoca quem são os trabalhadores, qual é o trabalho, 0 estudo e o lazer e o que está por traz do trabalho do adolescente. As entrevistas foram realizadas e gravadas após o consentimento individual dos jovens e de seus responsáveis legais e o estudo foi submetido ao Comitê de Ética de Pesquisa com Seres Humanos da EERP-USP.

\section{QUEM SÃO OS TRABALHADORES}

Os sujeitos pesquisados são meninos, vinculados a uma instituição que media a inserção no mercado de trabalho de adolescentes do sexo masculino. Ao considerarmos a alteração da legislação referente a idade mínima, de 16 anos para a inserção no mercado de trabalho, $70 \%$ dos adolescentes de nosso estudo encontram-se legalmente trabalhando, enquanto $30 \%$ estão abaixo do limite permitido por lei. Caso se considere o Estatuto da Criança e do Adolescente - ECA, cujo limite de idade é de 12 anos para o trabalho aprendiz e 14 anos para a efetiva entrada no mercado de trabalho, encontram-se dentro da legalidade para trabalhar. Estes trabalhadores não são jovens desprovidas de lar ou de família, todos tem famílias constituídas (independente do modelo familiar), tem casa, e freqüentam regularmente a escola.

Também não trabalham em substituição a seus pais, mas talvez para complementar a renda familiar, uma vez que a totalidade dos pais e $70 \%$ das mães dos adolescentes trabalham fora e $30 \%$ das mães fazem somente o serviço doméstico, não agrupando funções, como as demais. As ocupações dos pais e mães dos adolescentes entrevistados são tipicamente urbanas, apresentando uma grande variedade, tanto no que diz respeito à qualificação necessária para desenvolver a atividade, quanto no tocante a remuneração obtida pelo trabalho. Assim, têm-se pedreiros, mecânicos, vendedores, empregadas domésticas, costureiras, cabeleireiras, entre outras. Há uma semelhança nos dados em relação aos motivos, justificativas, idade de ingresso ao mercado de trabalho, escolaridade.

De um modo geral, todos os adolescentes tem condições de moradia razoavelmente aceitáveis, residindo geralmente em casas financiadas pelo governo, com um número de cômodos girando em torno de dois ou três quartos, sala, cozinha e banheiro. Esses dados não indicam uma necessidade expressa dos adolescentes para estarem trabalhando, uma vez que todos estudam, têm hábitos urbanos, moram com a família em casas relativamente cômodas, numa cidade de médio porte, com acesso a diversos setores e serviços. 0 que os estaria levando então ao mercado de trabalho? Chega-se ao que parece ser a motivação mais imediata, ou seja, a renda familiar.

Embora a pobreza seja inegavelmente um fator, a extensão em que as crianças e adolescentes são induzidas a trabalhar é também determinada pelo sistema de produção e pela correspondente estrutura do mercado de trabalho. Essas crianças e adolescentes trabalham de acordo com sua capacidade (ou não), e seu trabalho faz parte de um processo de socialização. Esse trabalho pode denotar desigualdade. É comum também os salários dos adultos da família serem tão baixos que os outros membros são forçados a contribuir com trabalho para suprir as necessidades de sobrevivência da família.

A origem do trabalho do menor está possivelmente relacionada à pobreza familiar e sua inserção no mercado de trabalho formal ou informal surge como meio de garantir/auxiliar a sobrevivência da família. A contínua depreciação dos salários vem impondo crescentemente 0 ingresso de mulheres e crianças nos vários setores de trabalho, como um meio de angariar recursos de modo a ampliar a renda ${ }^{(4)}$. 
Em publicação da OIT, sob coordenação de Elías Mendelievich, são apontados alguns determinantes para o trabalho precoce, a saber: "...la miseria en que vive y contribuir así a satisfacer sus necessidades esenciales. Hasta la más modesta remuneración, en dinero o en especie, será apreciada ...También está el deber moral, inculcado por el ambiente, de trabajar desde temprana edad por solidaridad com el grupo familiar, para compensar en lo posible la carga económica que él miesmo representa y ayudar a mantener al resto de su familia...el deseo de los padres de mantener a los niños ocupados, fuera de la calle, para que no caigan en la vagancia, com todas sus secuelas...También pode ocurrir que los niños empiecen a trabajar porque les va mal en la escuela y no les queda outra alternativa..."(5).

Em suma, os motivos para o trabalho precoce podem ser definidos como pobreza, necessidade de colaborar com os pais em atividades econômicas realizadas no domićlio, desejo dos pais de que trabalhem, necessidade de ganhar a vida por si mesmos, aliado a consideração de que é melhor trabalhar do que ficar ocioso.

Apenas uma pequena minoria da população de menos de 17 anos tem uma experiência enriquecedora no mercado de trabalho, do ponto de vista de oportunidades futuras, em que, trabalhar para a grande maioria dos jovens, significa mais uma estratégia pessoal ou familiar de sobrevivência do que uma iniciação que pode abrir as portas para os bons empregos do mercado de trabalho no futuro. Entrar na força de trabalho, para muitos, significa sacrificar um pouco o futuro, uma vez que trabalham e estudam ao mesmo tempo ou deixam a escola em função do trabalho. 0 convívio generalizado com o subemprego, desemprego, rotatividade, condições precárias de trabalho, aliado a poucas oportunidades de aprendizado e treinamento, socializa a maioria dos menores para as piores atividades do mercado de trabalho e impõe barreiras adicionais para 0 acesso aos bons empregos ${ }^{(4)}$.

A causa determinante que todos os adolescentes de nosso estudo, sem exceção, apontam, é o auxilio financeiro a família, que vai aparecer tanto com a complementação de dinheiro para pagamento das despesas familiares, quanto para aquisição de bens de consumo diretamente para os jovens trabalhadores: pra ajudar minha mãe e ganhar o meu dinheiro também (E1); pra me manter nas roupas, comprar roupa, calçado, fazer uma festinha com os amigos (E2); pra ajudar a minha família, um pouco também pra ajudar a mim, comprar minhas coisas, que eu preciso (E3).

0 discurso a favor do trabalho infanto-juvenil, além da necessidade de complementação de renda da família, aponta sua condição de fator de aprendizado e qualificação, ou seja, trabalho pedagógico voltado não para a produção de bens e serviços, mas para a formação profissional do jovem.

Esse cunho de formação (trabalho-aprendizagem), embora não muito claro na cabeça dos adolescentes transparece também em sua falas, contudo, parece-nos que não há distinção do trabalho que realizam com o trabalho desenvolvido pelos adultos, acrescentando nada ou muito pouco à educação profissional, ocupando o tempo que poderia ser destinado aos estudos ou brincadeiras, base para o desenvolvimento saudável e formação da estrutura do futuro adulto.

\section{QUAL É O TRABALHO}

0 trabalho adolescente pesquisado é exercido no setor de serviços, classificado geralmente como de apoio, denominado como de menor complexidade, "mais fácil", não sendo, contudo, trabalho específico para a categoria infanto-juvenil, apesar de ter se popularizado como tal, podendo ser exercido por adultos, não sendo menos leve, menos perigoso ou menos insalubre pelo fato de ser desenvolvido por adolescentes. No mundo de trabalho adulto corresponde a função de ajudante. Os estabelecimentos que os contratam são regularmente constituídos e tem em seu corpo de funcionários os adolescentes recrutados pela Instituição, trabalhando no lugar de adultos, ou seja, é um serviço contratado no mercado de trabalho. Na intermediação da instituição da relação de trabalho, um dos aspectos a considerar é que esses adolescentes não têm carteira assinada. A legislação trabalhista prevê as condições para o trabalho do adolescente e existe um setor específico da fiscalização (embora haja ausência de controle e fiscalização na maioria das vezes) apto a cobrar o cumprimento desta legislação. Alertamos para 0 ato ilusório do caráter formador para o ingresso do jovem no mercado de trabalho, que, mascarando-se de aprendizado, oculta a verdadeira essência da inserção precoce do adolescente no trabalho, ou seja o benefício da relação empregado-empregador, em que o primeiro subordina-se ao oferecido pelo mercado porque necessita trabalhar, e o segundo, como tem condições de escolher a mão-de-obra, estabelece o valor que quer pagar, lucrando com a possibilidade do não pagamento dos encargos determinados pela legislação trabalhista.

0 trabalho dos adolescentes em $70 \%$ dos casos ocupa uma jornada diária de oito horas, habitual no mundo de trabalho adulto e $30 \%$ deles trabalha em jornada diária de quatro horas, com um número de dias trabalhados na semana de cinco. 0 fato de trabalharem em jornadas de trabalho iguais as dos adultos, em tempo integral, com os mesmos dias na semana, aliado a freqüência na escola no período noturno, denotam o caráter sofrido do cotidiano de trabalho dos adolescentes entrevistados.

Por mais que as atividades que exerçam sejam consideradas simples, exigem um mínimo de escolarização e de 
vivência do meio escolar, o que é dificultado pela relação trabalhoescola, uma vez que a única opção que se apresenta ao adolescente trabalhador é o ensino noturno, marcado pelas dificuldades provenientes do cansaço, sono, pouca concentração ou da falta de tempo para estudar em casa e realizar tarefas fora da sala de aula.

Nos países em desenvolvimento o trabalho precoce é uma questão de sobrevivência para o menor e sua família, aponta que a situação de pobreza não se elimina por decreto, que existe a demanda de empregos de menores para uma renda de subsistência e a oferta de trabalho pouco qualificado e barato, onde os menores são trabalhadores dóceis, obrigados a aceitar em silêncio as condições de trabalho, os salários, a instabilidade e a insegurança que the são oferecidos (semelhante ao trabalhador adulto, atualmente) ${ }^{(6)}$.

No trabalho desenvolvido pelos jovens de nosso estudo, predomina a informalidade nas relações trabalhistas, as empresas não estabelecem contratos formais de trabalho. 0 rendimento é estável e corresponde a um salário mínimo, contudo, a falta de vínculo legal deixa o adolescente desassistido em relação aos seus direitos, tais como, repouso remunerado, vale-refeição, férias, décimo terceiro salário, assistência médica e previdenciária.

No contexto que tentamos abordar aqui, o trabalho infantojuvenil é considerado rotina, é entendido como rito de passagem para a vida adulta, o adolescente se percebe adulto e importante, porque já produz, tem autonomia financeira em relação a seus pais, algumas vezes mesmo, ganhando até mais do que eles. Esse é um processo de adultização, em que 0 adolescente assume papéis sociais destinados ao adulto, em nossa cultura. Em vez de consumidor da renda familiar passa a ser provedor. Entretanto, essa situação de adultização não é acompanhada por um processo de amadurecimento psicológico, o que possivelmente trará prejuízos afetivos e intelectuais ao jovem.

Há uma evidente distorção do lugar da criança na sociedade, imputando-se a ela o papel de provedor (ou co-provedor) da família, substituindo em parte a função dos adultos ${ }^{(7)}$. Não se subestima a condição financeira, o que se questiona é se a única alternativa é colocar os filhos para trabalhar precocemente. Essas questões devem ser compreendidas a partir do ponto de vista social, não do individual, pois como apontamos anteriormente, não é a família que inventa o trabalho precoce de seus filhos para aumento da renda, existe uma demanda de mercado para este trabalho, então, o que ela faz é utilizar os meios legitimados socialmente para resolver seu problema de sobrevivência.

Neste tipo de inserção ao trabalho, não há mobilidade ou ascensão ocupacional, ou seja, o adolescente fará parte do mundo do trabalho, mas não retirará dele um aprendizado que lhe permita ascensão, atuando em atividades cujo ponto terminal, possivelmente, será o mesmo do início do trabalho.
Quando analisamos a função de treinamento oferecida como condição pela instituição, lembramos das críticas na literatura para esta questão: "à medida que a profissionalização se esgota na domesticação, torna-se deseducativa; à medida que supõe determinar o mercado de trabalho, torna-se ingênua e incompetente; quando o treinamento não elabora o compromisso com o direito ao trabalho e à qualidade de vida, não se ultrapassa a noção instrumentalista de mão-de-obra/força-de-trabalho; quando se exalta em excesso as funcionalidades do homem treinado, porque mais aberto as socializações necessárias ao processo produtivo, o treinamento aparece como estratégia de desmobilização"(8) .

\section{O ESTUDO E O LAZER}

Antes de abordarmos a escola propriamente dita, faz-se necessário enfocarmos um aspecto mais abrangente, que é o entendimento sobre a educação. Muito freqüentemente, educação é tomada como essencialmente um problema de recursos humanos para o desenvolvimento, sem perceber-se que tal postura ajoelha a educação aos pés da economia e do mercado de trabalho, reduzindoa à função de preparadora de mão-de-obra, correndo-se o risco de acreditar que a educação faz todos os milagres, até mesmo criar empregos $^{(8)}$.

Olhar o trabalho a partir da educação é reconhecê-lo como parte integrante da realização educativa de qualquer pessoa, porque cidadania sem trabalho é vazia. A sobrevivência material, de modo geral, passa pelo trabalho, então, preparar-se para o trabalho não pode significar algo de relevância duvidosa.

É importante ressaltar para que fim se pensa educação, se é na ótica dos recursos humanos, estará se educando para reduzir o homem a força de trabalho, a mão-de-obra, a matéria produtiva em vez de produtor. Contudo, é preciso pensar que recursos humanos capacitados são essenciais para o desenvolvimento de um país. A educação é condição necessária, mas não suficiente para o desenvolvimento de um povo. 0 treinamento de recursos humanos pode levar à eficiência (domínio de instrumentos) mas não à eficácia (realização dos fins) $^{(8)}$.

0 conteúdo mais próprio da educação é o desdobramento das potencialidades de autodeterminação, pois o educador que não promove a auto-educação do educando, precisamente domestica. E cidadania contém mais do que tudo a noção de conquista de seu lugar ao sol, não às custas dos outros, mas com os outros. Homem não é coisa que se fabrique, é ser que se faz, não resultante de treinamento, mas processo de formação ${ }^{(8)}$.

Educação não cria empregos produtivos, não reduz a abundância de mão-de-obra, e nem sempre consegue reduzir males 
causados pela pobreza material, entretanto, permanece a crença de que educação é componente insubstituível do processo de desenvolvimento. Então, mesmo que não seja condição suficiente, é necessária. A educação não pode secundarizar o trabalho, embora deva enfocá-lo na trajetória da cidadania, pois mesmo que seja instrumento de sustentação do homem é também realização humana.

A educação, como meio de consolidação do direito ao trabalho, não pode vê-lo na condição de estorvo ao processo educativo. 0 trabalho aparece como expressão sócio-econômica, pois é através dele que garantimos a sobrevivência material, produzimos a riqueza econômica e permitimos o processo de acumulação. Esta realidade coloca para a educação o desafio de não se alienar da vida do trabalho e sobretudo de transformar o trabalho de luta pela sobrevivência em direito humano e realização da dignidade social.

Entretanto, em relação a escola, percebemos que alguma coisa não vai bem, quando analisamos a relação idade-série (em que a maioria dos adolescentes apresenta-se com idade maior do que aquela que deveria apresentar em relação a série de estudo), derivada da repetência escolar, associada ao próprio sistema educacional e ao trabalho exercido precocemente. Os adolescentes apontam como fatores para o problema a falta de interesse e a dificuldade em aprender, bem como ao cansaço ocasionado pelo trabalho: cansa mais com o trabalho pra ir pra escola (E1); tenho dificuldade de aprender mais agora (E3); eu tava desistindo quase de estudar, porque estava muito cansado (E9).

A universalização da educação básica deveria partir, sempre que possível, da necessidade de trabalhar, pois o processo de autodeterminação educativa não pode se fazer fora da identidade cultural do educando, se esta identidade se confunde com seu mundo do trabalho, esse mundo deveria ser a parte central do currículo, não para subjugar a educação ao mercado, mas para retirar das determinações do mercado a substância política de sua missão essencial, ou seja, encontrar instrumentos de concretização da cidadania ${ }^{(8)}$.

Essa realidade só vai mudar quando houver uma definição e implantação de uma política de formação profissional no contexto da educação como um todo (que parece apontado pela esfera governamental, ao menos na mídia, como implementação das novas diretrizes da educação brasileira, mas que carecem de acompanhamento para sabermos se de fato traz alguma inovação para o jovem trabalhador), "em que o trabalho, forte elemento instigador de conhecimento, seja incorporado ao processo educativo, na qual a formação profissional não substitua a formação básica, mas faça parte do processo regular de ensino, em que o trabalho educativo seja entendido como a atividade laboral”(9)

A grande mistificação talvez esteja na idéia de que 0 trabalho exercido pelas crianças e jovens é aprendizagem e, por esse motivo, talvez possa ficar em detrimento ao estudo. Essa é socialmente uma visão arraigada, porque há uma construção histórica em torno dos benefícios do trabalho, que podemos ilustrar através de ditos populares como "Deus ajuda quem cedo madruga", ou "o trabalho dignifica o homem", entre outros. Hoje em dia, essa visão talvez seja a mais equivocada, em função do desenvolvimento tecnológico do trabalho contemporâneo, que cada vez mais exige requisitos educacionais para incorporação do trabalhador ao mercado.

Existem ainda outras atividades importantes na infância e adolescência, como o jogo, a brincadeira, a prática de esportes, que associadas a participação na escola, desenvolvem de forma livre e espontânea, ou ainda orientada, a imaginação, a criatividade, o relacionamento em grupo, a convivência com o diferente.

Quando a criança ou o adolescente trabalham, sobra muito pouco ou nenhum tempo para brincar ou praticar esportes, uma vez que seu dia é preenchido pelo trabalho e pela escola. Alguns, quando ainda conservam alguma motivação, brincam ou praticam esportes nos fins de semana (a espelho dos adultos contemporâneos), as vezes nem isso, o que confirma a influência não muito benéfica do trabalho em sua vida.

\section{O QUE ESTÁ POR TRÁS DO TRABALHO DO ADOLESCENTE}

Neste momento procuramos refletir sobre os fenômenos sociais mais abrangentes que aparecem como causas sociais, econômicas, institucionais e individuais para o trabalho do adolescente, a saber: a pobreza, os programas de geração de renda, a distribuição de renda nacional, a ausência de política governamental para a educação, as transformações no mundo do trabalho e a ideologia que sustenta a concepção do trabalho.

A concepção do capital sobre o trabalho se constrói, portanto, mediante um processo que o reduz a uma mercadoria, a um objeto. A representação do trabalho se iguala à ocupação, à tarefa, ao emprego simplesmente. Perde-se a dimensão de que o trabalho é uma relação social - que, por um lado, é uma relação de força, de poder, e, de outro, é o que define o modo humano de existência, e que, enquanto tal, não se reduz à atividade de produção material para responder à reprodução físico-biológica (mundo da necessidade), mas envolve as dimensões sociais, estéticas, culturais, artísticas, de lazer, entre outras (mundo da liberdade) ${ }^{(9)}$.

Os programas de geração de renda para adolescentes, aqui entendidos como, de um lado, a oferta de trabalho possível (mercado informal, formal, na zona urbana ou rural) e de outro a 
demanda de mão-de-obra adolescente representada pelo universo de agentes que a buscam, como a família, empresas, atravessadores, agenciadores, organizações governamentais e não-governamentais, que articulam tais programas, tornando-se essenciais na medida em que a escola não dá conta da formação profissional e a situação econômico-financeira empurra o adolescente para o mercado de trabalho.

Algumas questões são apontadas na literatura para se entender o significado dos programas de geração de renda para adolescentes, a saber: serve como meio de ampliação da renda familiar, preenche o tempo livre de forma sadia, melhora as condições de vida da família, melhora o rendimento escolar, favorece a possibilidade de usufruir de bens culturais, é prática de exercício da cidadania $^{(9)}$

Estes programas acreditam estar investindo nos adolescentes pobres e fracassados, que uma vez na escola, precisam ocupar seu tempo livre com atividades e ocupações que não permitam a vadiagem. Além disso, acredita-se na complementação da renda familiar. Além de "ajudar em casa", o adolescente trabalhador é mais uma economia para a família, que deixa de ter gastos com ele em vestuário, lazer, material escolar, entre outros.

Esses adolescentes que trabalham no meio urbano inseridos no mercado formal acabam limitando-se ao desenvolvimento de tarefas de apoio na prestação de serviços, como embaladores, empacotadores, repositores de mercadorias e officeboys, como no caso dos jovens deste estudo.

Para o adolescente que está descobrindo seu espaço no mundo, assumir sua função de trabalhador nestas ocupações organizadas sempre com a maior "boa vontade", pode levar, pelas condições encontradas no trabalho, a sérios prejuízos na construção de sua identidade, enfrentando conceitos que ainda não são de seu domínio, apesar de propícios da idade, como a baixa auto-estima, 0 desinteresse, podendo chegar ao abandono do trabalho, problemas de relacionamento, entre outras dificuldades.

Outra dificuldade dos programas de geração de renda é 0 enfoque centrado exclusivamente no adolescente, desarticulado de ações sócio-educativas que envolvam a família. Ou seja, quando não há postos de trabalho e salários condizentes para os adultos proporcionarem o sustento da família, continua a haver demanda pelo trabalho do adolescente.

As atividades de geração de renda para o adolescente, seja na forma de programas, ou na forma de instituições mediadoras para o mercado de trabalho, facilitam e exigem a disciplina, o controle e a aceitação do menor trabalhador pela sociedade. É necessário que se mantenha dócil, obediente, disposto para o trabalho, mantendo a relação de dominação/subordinação exigida pelo modelo social que vivenciamos, para que este se perpetue.
Um fator contextual, complexo e muito abrangente que também determina o trabalho do jovem é a concentração de renda em nosso país, que pode ser considerada uma das piores distribuições de renda, expressa nos baixos salários, nos índices de desemprego, no número de excluídos vivendo a margem da sociedade, nos indicadores de educação, saúde, mortalidade infantil, esperança de vida e principalmente, no número de crianças e jovens trabalhando.

A relação direta entre o que acabamos de afirmar e 0 trabalho precoce se dá na medida em que, com a precarização de relações e condições de trabalho, com os salários cada vez mais baixos e o custo de vida cada vez mais alto, as famílias de menor renda adotaram uma das estratégias mais conhecidas e mais socialmente aceitas para superar as limitações dos rendimentos individuais (dos adultos da família) extremamente baixos, ou seja, propiciam o ingresso no mercado de trabalho do maior número possível de membros da família.

Outro aspecto que não pode se deixar de mencionar como determinante para o trabalho precoce é a ideologia em relação ao trabalho, que considera essa atividade a mais nobre exercida pelo homem, como panacéia para todos os males, como remissão para o crime e a marginalidade, como única forma legítima de aquisição de riquezas e de acesso aos meios da vida ${ }^{(7)}$.

Essa ideologia não discute se todo trabalho é bom para qualquer pessoa, independente de sua natureza leve ou penosa, inócua ou perigosa, saudável ou insalubre. Não faz diferenciação entre quem pode e quem deve trabalhar, ou para quem o trabalho deve ser optativo ou proibido. Acontece que essa ideologia é aplicada aos pobres, são estes que lançam mão do recurso e do argumento moral do trabalho. Ao mesmo tempo que é estratégia de sobrevivência, também o é de inserção social para aquelas famílias excluídas das oportunidades sociais.

Nesse sentido, é apenas no discurso, como ideal a ser atingido que o trabalho aparece como a atividade mais nobre da humanidade, sendo na realidade, necessidade vital para alguns muitos e forma eficaz de exploração para outros.

Há ainda que se considerar que, geralmente, os pais de menores que trabalham, trabalharam também eles desde muito jovens e raramente freqüentaram a escola. Ao ver muitos adultos desempregados ou subempregados, mesmo tendo estudo, consideram que é melhor que seus filhos aprendam um ofício além da escola, para não correr o risco de ficarem na mesma situação. Os adolescentes tendem a acreditar que o trabalho os valoriza diante de si próprios e de seus pais, Ihes permite adquirir uma independência financeira e psicológica e ajudar suas famílias, mesmo que essa aparente conquista tenha um preço a pagar um tanto quanto alto. 


\section{REFERÊNCIAS BIBLIOGRÁFICAS}

1. Veiga JPC. A questão do trabalho infantil. São Paulo: ABET; 1998.

2. Marx C. 0 capital. São Paulo: Ed. Formar.

3. Minayo MC de S. 0 desafio do conhecimento: pesquisa qualitativa em saúde. $4^{a}$ ed. São Paulo: Hucitec-Abrasco; 1996.

4. Costa AG da. 0 estatuto da criança e do adolescente e o trabalho infantil no Brasil: trajetória, situação atual e perspectivas. Brasília (DF): OIT; 1994.

5. Organización Internacional del Trabajo. Oficina Internacional del Trabajo. El trabajo de los niños. Ginebra (SZ): OIT; 1980.
6. Derrien JM. A fiscalização do trabalho e o trabalho infantil. $2^{\mathrm{a}}$ ed. Brasília (DF): OIT; 1993.

7. 0 trabalho tolerado de crianças de até catorze anos. Boletim DIEESE 1997 abril; (93).

8. Demo P. Educação básica e trabalho do menor: discutindo o trabalho a partir da educação. IPEA/IPLAN/CPR. Brasília (DF): OIT; 1985.

9. Pereira I. et al. Trabalho do adolescente: mitos e dilemas. São Paulo (SP): FUNDACENTRO; 1997. 